\title{
On the relationship between indenation hardness and modulus, and the damage resistance of biological materials.
}

\author{
David Labonte ${ }^{\mathrm{a}, *}$, Anne-Kristin Lenz ${ }^{\mathrm{b}}$, Michelle L. Oyen ${ }^{\mathrm{a}}$ \\ ${ }^{a}$ The NanoScience Centre, Department of Engineering, Cambridge, UK \\ ${ }^{b}$ University of Applied Sciences, Bremen, Germany
}

\begin{abstract}
The remarkable mechanical performance of biological materials is based on intricate structure-function relationships. Nanoindentation has become the primary tool for characterising biological materials, as it allows to relate structural changes to variations in mechanical properties on small scales. However, the respective theoretical background and associated interpretation of the parameters measured via indentation derives largely from research on 'traditional' engineering materials such as metals or ceramics. Here, we discuss the functional relevance of indentation hardness in biological materials by presenting a meta-analysis of its relationship with indentation modulus. Across seven orders of magnitude, indentation hardness was directly proportional to indentation modulus, illustrating that hardness is not an independent material property. Using a lumped parameter model to deconvolute indentation hardness into components arising from reversible and irreversible deformation, we establish criteria which allow to interpret differences in indentation hardness across or within biological materials. The ratio between hardness and modulus arises as a key parameter, which is a proxy for the ratio between irreversible and reversible deformation during indentation, and the material's yield strength. Indentation hardness generally increases upon material dehydration, however to a larger extend than expected from accompanying changes in indentation modulus, indicating that water acts as a 'plasticiser'. A detailed discussion of the role of indentation hardness, modulus and toughness in damage control during sharp or blunt indentation yields comprehensive guidelines for a performance-based ranking of biological materials, and suggests that quasi-plastic deformation is a frequent yet poorly understood damage mode, highlighting an important area of future research.
\end{abstract}

Keywords: Structure-function relationships, Biomechanics, Wear, Hydration

\section{Introduction}

In search for inspiration for the design of novel materials with enhanced properties, biological materials receive an increasing amount of attention (e.g. 1-5). Two features of these materials stand in stark contrast to 'classic' engineering materials: first, they are hierarchical in design, that is they are constructed from multiple building blocks arranged on characteristic length scales ranging from a couple of nanometres to a few millimetres. Second, the structural arrangement and properties of these components are tailored to specific functional demands.

A thorough understanding of how the arrangement and properties of individual components determine the performance of the 'bulk' materials is a prerequisite for any attempt at replicating their functionality. Hence, mechanical and structural characterisation methods traditionally developed for and applied to engineering materials are increasingly used to study biological materials. Among these, instrumented indentation has been particularly popular, due to the relative ease of use and its ability to accurately measure material properties on various length scales (6-8). In biological materials, instrumented indentation is frequently used as a tool to relate structural changes, for example degree of mineralisation, to variations in material properties, such as fracture toughness, elastic modulus, and hardness. These properties, in turn, determine performance and hence the adaptive value of the structural changes in ques- 
tion, and therefore can shed light on critical structurefunction relationships.

Fracture toughness, $T$, quantifies a material's resistance to crack initiation and propagation, and is superseding 'strength' as the property most associated with high-performance materials $(9,10)$. The hierarchical design and the ensuing complexity of biological materials necessitates a careful execution and application of the existing indentation methodology (11). However, instrumented indentation remains an unrivalled method for the evaluation of toughness, in particular in biological materials which are frequently too small or irregular to allow the fabrication of 'standardised' specimen required for more conventional fracture tests (8).

The elastic modulus quantifies the resistance to elastic (reversible) deformation. In contrast to toughness, a large modulus is not necessarily desired (for example, adhesive structures need to be somewhat compliant), so that a direct link between its magnitude and performance is often not straightforward. Most studies assume isotropic behaviour of biological materials, i. e. a mechanical response that is independent of the testing direction. However, it is frequently acknowledged that this assumption is more practical than accurate, and most of the literature hence reports an indentation modulus, $E_{\mathrm{I}}$, which is equal to the plain strain modulus, $E^{\prime}$, if the modulus of the indenter is much larger than that of the material, and if the material is isotropic.

Hardness is probably the most commonly measured, but least understood of the material properties that can be assessed by instrumented indentation. Despite an increasing body of literature which has highlighted that hardness is a complex property that needs to be interpreted with care (see e.g. 6, 12-17), it is still often taken as a proxy for the resistance to 'plastic' (i.e. irreversible) deformation. This interpretation has been particularly popular in the more biological literature, perhaps because it provides a straightforward link to functional and hence ecological relevance. Hardness has long been a property of considerable importance in engineering materials: it is an index of strength (18) and - in combination with toughness - of brittleness (19). Hardness is frequently associated with a material's resistance against being penetrated (i.e. elastically deformed), spread (i. e. irreversibly deformed) or scratched (i.e. fractured) (20). Clearly, the physical mechanisms involved in these processes differ. What is the functional meaning of indentation hardness?

In this article, this question is addressed by presenting a comprehensive meta-analysis of published data on indentation modulus, $E_{\mathrm{I}}$, and indentation hardness, $H_{\mathrm{I}}$, of diverse biological materials. We investigate the relationship between the two properties, which is then interpreted with a series elastic-plastic deformation model. This analysis provides guidelines for a careful interpretation and comparison of indentation hardness across and within biological materials, and highlights potential pitfalls. Next, we focus more specifically on the functional relevance of $T, E_{\mathrm{I}}$ and $H_{\mathrm{I}}$ for the avoidance and containment of mechanical damage introduced by 'blunt' or 'sharp' contacts, ${ }^{1}$ and discuss the competition between quasi-plasticity and fracture in biological materials. Quasi-plasticity emerges as the dominant damage mode for most biological materials, which is controlled not by indentation hardness, but by its ratio with the indentation modulus.

\section{Analysis \& Discussion}

The correlation between indentation hardness and modulus

Indentation hardness and modulus of various biological materials were assembled from the literature (2289 , all data are available in the supplemental material). Across seven orders of magnitude, indentation hardness was directly proportional to indentation modulus (figure 1), with a proportionality constant of approximately $0.05, H_{\mathrm{I}}=0.046 E_{\mathrm{I}}^{1.03}$ (reduced major axis regression on log-transformed data, $95 \%$ confidence intervals (CI) $[0.043 ; 0.050]$ and $[1.01 ; 1.06])$. The strength of the correlation, $\mathrm{R}^{2}=0.96$, is somewhat deceptive, as the regression was performed on log-transformed data. Some of the variation in the ratio $H_{\mathrm{I}} / E_{\mathrm{I}}$ across wellrepresented materials is captured in Table 1. The data used in the regression include properties measured with different indenter geometries, and in hydrated or dehydrated conditions. These factors are discussed further below.

A correlation between hardness and bulk, Young's and in particular shear modulus has also been reported for metals, bulk metallic glasses, ceramics and polymers (see e.g. 90-99), which can be qualitatively un-

\footnotetext{
${ }^{1}$ The distinction between sharp and blunt contacts is somewhat arbitrary - sharp indenters are those with a steep angle of the tangent at the point of contact. Irreversible deformation will necessarily precede cracking if the contact is sharp, while the deformation can remain dominantly elastic prior to fracture if the indenter is blunt. To a first approximation, spheres are blunt, and conical, Vickers, Berkovich and cube corner indenters are sharp.
} 


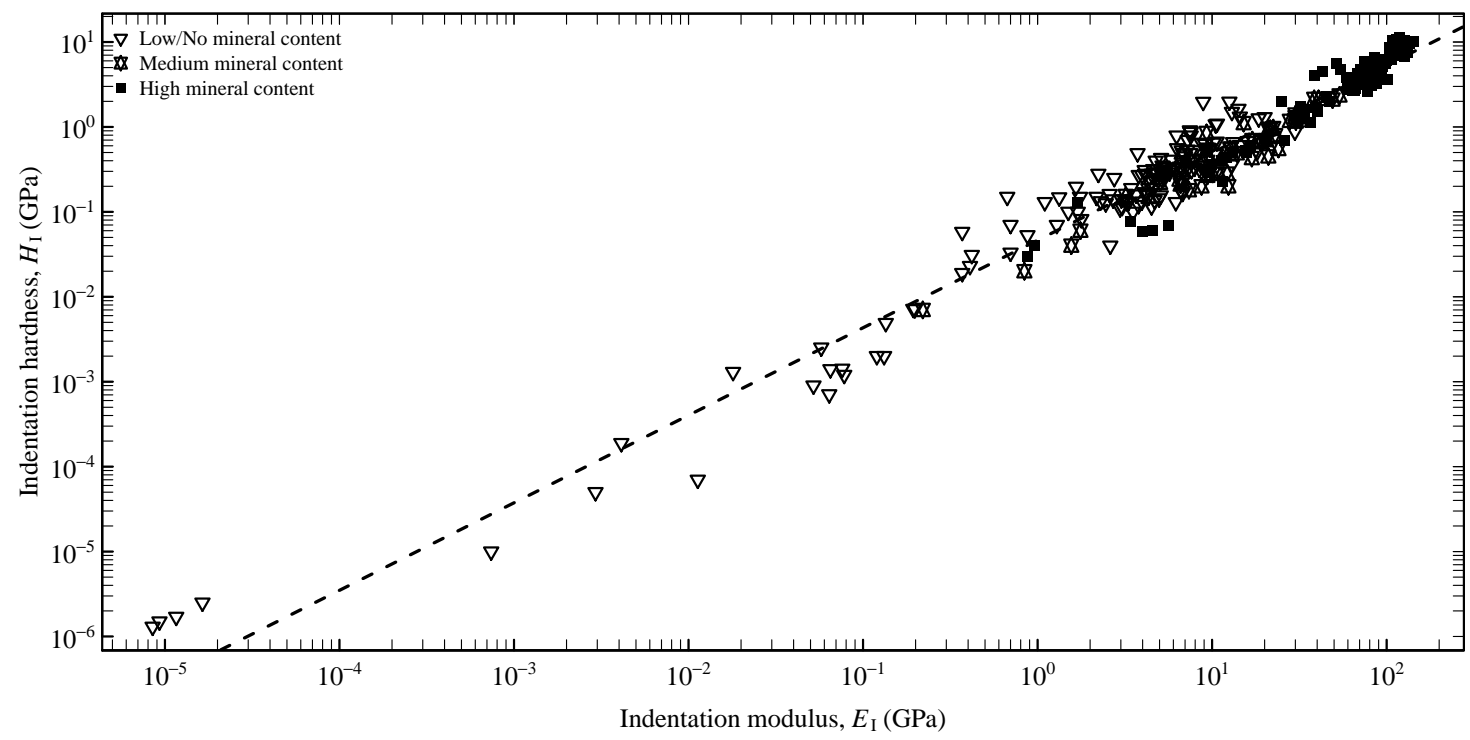

Figure 1: Across seven orders of magnitude, indentation hardness, $H_{\mathrm{I}}$, was directly proportional to indentation modulus, $E_{\mathrm{I}}$. The dashed line is the result of a reduced major axis regression on log-transformed values, $H_{\mathrm{I}}=0.046 E_{\mathrm{I}}^{1.03}(95 \%$ confidence intervals $(\mathrm{CI})[0.043 ; 0.050]$ and [1.01; 1.06], $\left.\mathrm{R}^{2}=0.96\right)$. An ordinary least-squares regression yielded a similar result, $H_{\mathrm{I}}=0.048 E_{\mathrm{I}}^{1.01}$ (95\% CI [0.045; 0.052] and [0.99; 1.03]. Thus, $H_{\mathrm{I}} \approx 0.05 E_{\mathrm{I}}$. Classification by mineral content was performed as described in Amini \& Miserez, 2013 (21).

derstood by considering two limiting cases: In rigidperfectly-plastic materials, all deformation is accommodated irreversibly, and hence no elastic energy is stored in the deformed material. In this limit, indentation hardness is indeed an accurate proxy for the resistance to irreversible deformation. If the yield stress is infinite, in turn, all deformation is accommodated reversibly, so that the mean contact pressure - and thus the indentation hardness - is entirely determined by the elastic properties of the material and the indenter geometry. The reality lies in between these two cases, so that indentation hardness is hardly ever independent of indentation modulus (but not vice versa. Notably, this problem cannot be circumvented by measuring the lateral extent of the residual impression as is done in 'traditional' hardness tests, because the elastic recovery occurs often dominantly in-depth, see e. g. 100, 101). The indentation hardness is determined by properties pertaining to the resistance against both irreversible and reversible deformation, and exploring its correlation with indentation modulus further therefore requires a mechanical model that accounts for both.

Using the classic framework of lumped parameter models, irreversible and reversible deformation may be assumed to be linked in series, as utilised by Sakai (14). In this simple model, the elastic component is charac- terised by an elastic modulus (represented by a spring), while the irreversible component is characterised by a 'true' resistance to irreversible deformation, $H$, which is equivalent to the mean contact pressure during the indentation of a rigid-perfectly-plastic material (represented by a slider). The respective constitutive relationships for perfectly plastic and purely elastic conical indentation can be combined to obtain (a detailed derivation can be found in the supplemental material, $14,17,102))$ :

$$
H_{\mathrm{I}}=\frac{H}{\left(1+\sqrt{H / E_{\mathrm{I}}} \sqrt{2 / \tan (\beta)}\right)^{2}}
$$

or equivalently

$$
H=\frac{H_{\mathrm{I}}}{\left(1-\sqrt{H_{\mathrm{I}} / E_{\mathrm{I}}} \sqrt{2 / \tan (\beta)}\right)^{2}}
$$

where $\beta$ is the equivalent cone angle of the indenter. A number of conclusions are immediately apparent from these equations:

1. As $H_{\mathrm{I}} / E_{\mathrm{I}} \rightarrow 0$, the indentation hardness converges to the 'true' hardness, i.e. $H / H_{\mathrm{I}} \rightarrow 1$ (figure $2 \mathrm{~A}$ ). Hence, indentation tests reasonably approximate resistance to irreversible deformation in materials with small 
Table 1: While indentation hardness, $H_{\mathrm{I}}$, and indentation modulus, $E_{\mathrm{I}}$, were linearly related across seven orders of magnitude, their ratio, the elasticity index $I_{\mathrm{E}}$, differed systematically across different materials, indicating different amounts of relative irreversible deformation, $h_{\mathrm{r}} / h_{\max }$ (calculated using the median values for $I_{\mathrm{E}}$ and eq. 3). Data are ordered by their elasticity index.

\begin{tabular}{|c|c|c|c|c|c|c|c|}
\hline & & Indentati & $\mathrm{Is}, E_{\mathrm{I}}(\mathrm{GPa})$ & Indentati & $\mathrm{s}, H_{\mathrm{I}}(\mathrm{GPa})$ & $I_{\mathrm{E}}$ & $h_{\mathrm{r}} / h_{\max }(\%)$ \\
\hline Material & $\mathrm{N}$ & Median & Range & Median & Range & Median & \\
\hline Crustacean Cuticle & 15 & 19.0 & $3.2-53.7$ & 0.45 & $0.15-2.35$ & 0.033 & 0.82 \\
\hline Dentin & 10 & 26.5 & $8.7-49.0$ & 1.00 & $0.20-2.10$ & 0.040 & 0.78 \\
\hline$\beta$-Keratin & 11 & 4.3 & $3.2-6.0$ & 0.19 & $0.13-0.41$ & 0.044 & 0.75 \\
\hline Mineralised with Calcite & 16 & 65.7 & $25.9-73.0$ & 3.35 & $0.69-4.70$ & 0.052 & 0.71 \\
\hline Insect Cuticle & 67 & 6.7 & 0.4-29.8 & 0.33 & $0.03-1.98$ & 0.054 & 0.70 \\
\hline Enamel/Enameloid & 16 & 96.0 & $62.7-131.2$ & 5.90 & $2.60-7.60$ & 0.057 & 0.68 \\
\hline Wood & 14 & 5.9 & 1.1-18.1 & 0.33 & $0.13-0.41$ & 0.063 & 0.65 \\
\hline Mineralised with Aragonite & 30 & 90.6 & $36.5-142.5$ & 5.40 & $1.13-11.40$ & 0.068 & 0.62 \\
\hline
\end{tabular}

values of $H_{\mathrm{I}} / E_{\mathrm{I}}$, for which they were originally developed and remain best-understood. For example, for ductile metals $H_{\mathrm{I}} / E_{\mathrm{I}} \approx 10^{-3}$, and hence the indentation hardness measured with Vickers or Berkovich tips is within $20 \%$ of the 'true' hardness.

2. As $H_{\mathrm{I}} / E_{\mathrm{I}} \rightarrow 1 / 2 \tan (\beta)$, the true hardness diverges, because the indentation hardness cannot exceed the elastic contact pressure, $H_{\mathrm{I}} \leq 1 / 2 E_{\mathrm{I}} \tan (\beta)$ (see figure $2 \mathrm{~A}$ ). We found several reports in contradiction with this limit (e.g. in 42, 53, 83), most likely explained by viscoelastic behaviour of the indented materials.

3. The indentation hardness depends on the indenter geometry. The influence of the effective angle is negligible when data obtained with Vickers, Berkovich or Knoop indentors are compared, but can be significant when results from indentations with cube corner or spherical indenters are included (a more detailed analysis of this dependence can be found in reference 14). We used eqs. 1 and 2 to rescale the data shown in figure 1 to Berkovich indentation hardness values, and found that the estimated relationship remained virtually unchanged, illustrating the robustness of the collated data (see supplemental material).

4. The 'true' resistance to plastic deformation, $\mathrm{H}$, depends on the ratio between indentation hardness and indentation modulus. Thus, a large indentation hardness does not imply a large resistance to irreversible deformation per se. As an illustrative example, the mandibles of West Indian dry-wood termites (Cryptotermes brevis) have a Berkovich indention hardness of $1.07 \mathrm{GPa}$, and an indentation modulus of $10.5 \mathrm{GPa}$ (34), implying a 'true' hardness of $17.8 \mathrm{GPa}$. Hydrated human enamel, in turn, has a Berkovich indentation hardness which is thrice as large $(3.21 \mathrm{GPa})$, but its 'true' hardness is almost two times smaller $(H=10.8 \mathrm{Gpa})$, because the in- dentation hardness is dominated by the large indentation modulus of $87.02 \mathrm{GPa}(35)$.

The correlation between indentation hardness and indentation modulus requires particular attention in materials with pronounced anisotropy or gradual changes in material properties. In order to illustrate this point, we briefly discuss the relationship between indentation hardness and modulus in the adhesive hairs (setae) of Chilean rose tarantulas (Grammostola rosea), indented at different angles relative to their longitudinal axis (103). While $H_{\mathrm{I}}$ varied by a factor of almost 30 (figure 2 B), a non-linear least-squares fit of eq. 1 suggested that much of this variation is explained by a change of the indentation modulus - most likely caused by the unidirectional orientation of reinforcing fibres in the adhesive setae themselves - and that the 'true' hardness is actually constant at $2.21 \mathrm{GPa}(95 \%$ confidence interval $(2.12 ; 2.33))$.

The previous discussion underlines that any interpretation of changes in $H_{\mathrm{I}}$ within or across structural biological materials requires care, and should at the very least include the ratio $H_{\mathrm{I}} / E_{\mathrm{I}}$. This ratio can also be used to calculate a 'true' hardness, a property independent of the modulus and indenter geometry, which represents the energy required to create a unit volume of irreversible impression (14), and thus provides additional comparative information about the mechanical performance of biological materials. The mechanistic origin of the increase of $H$ with $E_{\mathrm{I}}$ implied by the available data requires further clarification.

The verdict that indentation hardness is a hybrid measure characterising reversible and irreversible deformation is not new (see e. g. 6, 12-16), but has received relatively little attention outside the more technically oriented indentation literature. A related interpretation is 
A

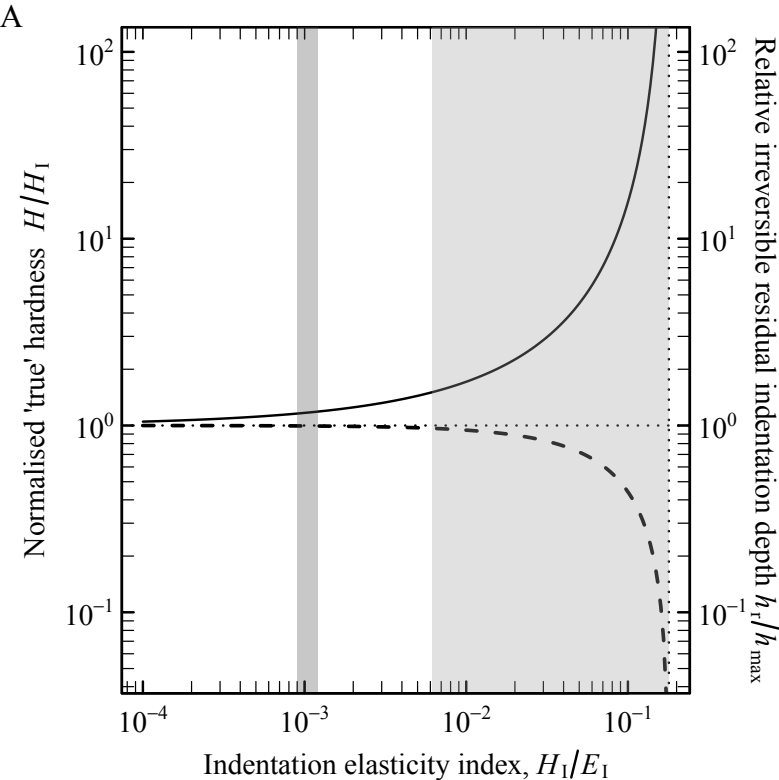

B

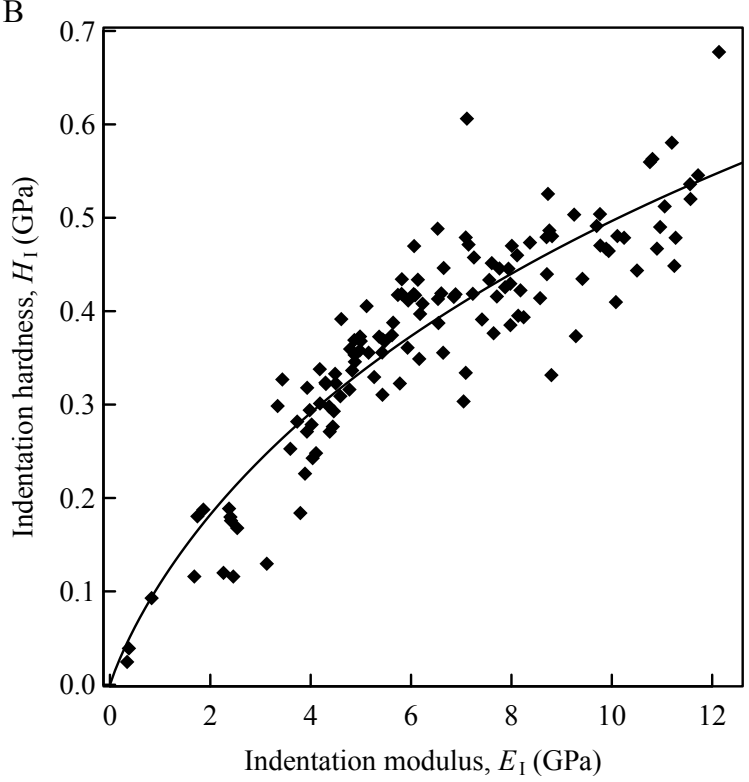

Figure 2: (A) The 'true' indentation hardness, $H$, can be estimated from the indentation elasticity index, $I_{\mathrm{E}}=H_{\mathrm{I}} / E_{\mathrm{I}}$, by assuming that reversible and irreversible deformation are linked in series (see text). The ratio $H / H_{\mathrm{I}}$ (solid line, eq. 2 with $\beta=19.7^{\circ}$ for a Berkovich indenter) approaches 1 in the limit of small $I_{\mathrm{E}}$, while it diverges as $I_{\mathrm{E}}$ approaches its maximum possible value set by the elastic contact pressure, $I_{\mathrm{E}} \leq \tan (\beta) / 2 \approx 0.18$ for a Berkovich indenter. As a consequence, the deformation transitions from dominantly irreversible for materials with small values of $I_{\mathrm{E}}$ to effectively completely reversible for large values of $I_{\mathrm{E}}$, as illustrated by the dashed line (eq. 3). The dark grey rectangle illustrates the range of $I_{\mathrm{E}}$ typical for ductile metals, in which $H / H_{\mathrm{I}}$ is close to one; the light grey rectangle indicates the range observed for biological materials. (B) As indentation hardness is a hybrid measure related to both irreversible and reversible deformation, changes in indentation modulus alone will change the measured indentation hardness. The adhesive setae of Chilean rose tarantulas were indented at different angles to their axis in order to study their anisotropy (103). The observed almost 30-fold change in indentation hardness is likely solely based on a change of the indentation modulus, as indicated by a non-linear least-squares fit of eq. 1 (solid line), which yielded a constant 'true' hardness of $2.21 \mathrm{GPa}(95 \%$ confidence interval $(2.12 ; 2.33)$ ).

that $H_{\mathrm{I}}$ is a measure for the work required to create a unit volume of residual impression (14), and that the ratio $H_{\mathrm{I}} / E_{\mathrm{I}}$ is thus proportional to the ratio between the irreversible and reversible work done during indentation $(13,14)$. As a consequence, $H_{\mathrm{I}} / E_{\mathrm{I}}$ may be interpreted as an 'elasticity index' $I_{\mathrm{E}}=H_{\mathrm{I}} / E_{\mathrm{I}}$ : Large values indicate a dominance of reversible deformation, and small values imply dominantly irreversible deformation (14). The elasticity of the contact can also be assessed from the slopes of the loading and unloading curves (104), or from the ratio between the residual indentation depth, $h_{\mathrm{r}}$, and the indentation depth at maximum load, $h_{\text {max }}$ (105). In the framework of the Oliver-Pharr analysis, this ratio is given by:

$$
\frac{h_{\mathrm{r}}}{h_{\max }}=1-2 \frac{I_{\mathrm{E}}}{\tan (\beta)}
$$

The direct proportionality between $H_{\mathrm{I}}$ and $E_{\mathrm{I}}$ across seven orders of magnitude implies that the elasticity in- dex is constant, $I_{\mathrm{E}} \approx 0.05$, and hence that around $3 / 4$ of the total deformation of biological materials during indentation with a Berkovich indenter is irreversible $\left(h_{\mathrm{r}} / h_{\max } \approx 72 \%\right.$, see figure $\left.2 \mathrm{~A}\right)$.

\section{The effect of hydration on indentation hardness and modulus}

There is ample evidence that the mechanical properties of biological materials are sensitive to hydration, which tends to decrease hardness and modulus, but increase toughness (e.g. 3, 22, 35, 60, 71, 106109). It is convenient to define the sensitivity to hydration, $S_{\mathrm{H}}$, as the relative change in indentation hardness/modulus upon dehydration, $S_{\mathrm{H}, H_{\mathrm{I}}}=\left(H_{\mathrm{I}, \mathrm{d}}-\right.$ $\left.H_{\mathrm{I}, \mathrm{w}}\right) / H_{\mathrm{I}, \mathrm{w}}$ and $S_{\mathrm{H}, E_{\mathrm{I}}}=\left(E_{\mathrm{I}, \mathrm{d}}-E_{\mathrm{I}, \mathrm{w}}\right) / E_{\mathrm{I}, \mathrm{w}}$, where the indices $w$ and $d$ indicate data from hydrated ('wet') and dehydrated ('dry') materials, respectively. Dehydration can affect the measured mechanical properties by a change in both structure and/or properties of the material, and hydrophobic and hydrophilic materials will 
take up different amounts of water, even if their ultrastructure is identical. The effects of these factors cannot be addressed with the presently available data.

A meta-analysis of data collated from the literature suggests that the sensitivity to hydration is largest for materials with small $H_{\mathrm{I}, \mathrm{w}}$ and $E_{\mathrm{I}, \mathrm{w}}$ (see figure 3). A regression of the combined data - from $0.007 \mathrm{GPa}$

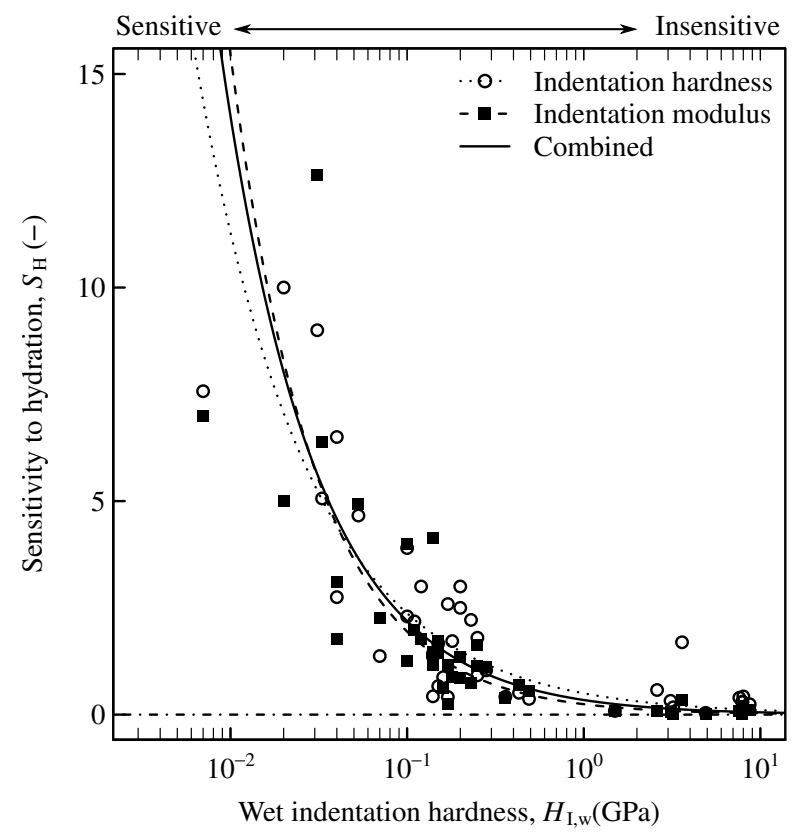

Figure 3: Biological materials are particularly sensitive to hydration if their hydrated indentation hardness or modulus is small (note the logarithmic $\mathrm{x}$-axis). The sensitivity to hydration is defined in this context as $\left(H_{\mathrm{I}, \mathrm{d}}-H_{\mathrm{I}, \mathrm{w}}\right) / H_{\mathrm{I}, \mathrm{w}}$ and $\left(E_{\mathrm{I}, \mathrm{d}}-E_{\mathrm{I}, \mathrm{w}}\right) / E_{\mathrm{I}, \mathrm{w}}$, i. e. $S_{\mathrm{H}}=0.2$ indicates a $20 \%$ increase in hardness and modulus upon dehydration, whereas $S_{\mathrm{H}}=0$ indicates no change. The lines are the result of reduced major axis regression on log-transformed data, separately for indentation hardness (dotted line), indentation modulus (dashed line), and both combined (solid line). The detailed results of the regressions are given in the supplemental material.

$<H_{\mathrm{I}, \mathrm{w}}<8.7 \mathrm{GPa}$ and $0.22 \mathrm{GPa}<E_{\mathrm{I}, \mathrm{w}}<125.7 \mathrm{GPa}$ - suggested that the sensitivity to hydration decreases with hydrated indentation hardness as $S_{\mathrm{H}}=0.34 H_{\mathrm{I}, \mathrm{w}}^{-0.81}$ $\left(\mathrm{R}^{2}=71 \%, 95 \% \mathrm{CI}(0.26 ; 0.42)\right.$ and $(-0.91 ;-0.71)$, respectively. An analogous result with respect to $E_{\mathrm{I}, \mathrm{w}}$ is given in the supplemental material). Indentation properties of dehydrated biological materials hence have to be interpreted with great care: First, they will almost always significantly deviate from the 'true' value - even stiff and hard materials with $H_{\mathrm{I}, \mathrm{w}}>4.5 \mathrm{GPa}$ (or $E_{\mathrm{I}, \mathrm{w}}>$ $90 \mathrm{GPa}$ ) change their indentation properties by up to $10 \%$ upon dehydration. Second, while it may be possi- ble to predict dehydrated from the hydrated properties, the inverse will be more error-prone.

As indention hardness is a hybrid measure of a material's resistance to irreversible and reversible deformation, a change in indentation modulus will also affect indentation hardness. In order to investigate if the effect of hydration on indentation hardness is explained by the associated change in indentation modulus, we estimated the 'true hardness' of hydrated materials via eq. 2 , and then predicted the indentation hardness of dry materials using eq. 1 . This procedure resulted in a significant underestimation of $H_{\mathrm{I}, \mathrm{d}}$ (by a factor of around 1.5, Wilcoxon signed-rank test, $\mathrm{V}=1112, \mathrm{p}=0.012$ ), suggesting that the 'true' resistance to irreversible deformation increased upon dehydration in most of the investigated materials. Hence, water generally acts as a 'plasticizer'.

\section{Damage control in biological materials}

In both biological and engineering contexts, indentation hardness is frequently used as a proxy for wear resistance, either directly, in ratio to indentation modulus, or in form of the property group $H_{\mathrm{I}}^{3} / E_{\mathrm{I}}^{2}$ (e.g. 21, 34, 36, 110-113). The diverse ways in which hardness can be related to wear resistance partly reflects the fact that wear is a complex and systemdependent phenomenon (114). As a consequence, different wear mechanisms are controlled by different parameter groups $(21,115)$.

Resistance to mechanical wear quantifies the propensity of a material to be permanently altered (damaged) by mechanical interactions with external bodies/particles, for example via quasi-plastic deformation (yield) or fracture (cracking). These two phenomena are governed by different physical processes, so that the material properties that determine wear resistance depend on the dominating damage mode. As it is unlikely that damage can be avoided altogether (for example, surface craters and cracks are abundant in hominid teeth, see ref. 116), wear resistance becomes a question of damage containment. Both quasi-plasticity and fracture give rise to a damage zone with a characteristic length (schematically shown in figure 4), which can be used to rank materials by their damage resistance. For simplicity, we assume (i) that the wear contact is frictionless, and (ii) that the plane strain modulus of the abrasive material is much larger than that of the abraded material (for a discussion including friction, see ref. 115). 
In ideal brittle materials, the damage zone arising from fracture is characterised by the length of a coneor penny-shaped crack, $c$, which scales as

$$
\begin{aligned}
& c_{\mathrm{b}} \propto\left(\frac{P}{\sqrt{G_{\mathrm{c}} E}}\right)^{2 / 3} \\
& c_{\mathrm{s}} \propto\left(\frac{P}{\sqrt{G_{\mathrm{c}} H_{\mathrm{I}}}}\right)^{2 / 3}
\end{aligned}
$$

for blunt and sharp contacts, respectively $(117,118)$. Here, $G_{\mathrm{c}}=T^{2} / E$ is the work of fracture, which is assumed to be independent of the crack length, and $E$ is the Young's modulus. The difference in the denominator, $E$ vs. $H_{\mathrm{I}}$, arises because cracks in blunt contacts extend during loading, while radial cracks in sharp contacts grow to their final length during unloading, driven by a residual stress field $\xi_{\mathrm{r}} \propto \sqrt{E / H_{\mathrm{I}}}(119)$.

The damage zone induced by quasi-plasticity, in turn, is characterised by the depth of the residual impression, $h_{\mathrm{r}}$. The Oliver-Pharr model can be used to find

$$
h_{\mathrm{r}}=\sqrt{\frac{P}{A_{1} H_{\mathrm{I}}}}\left(1-2 \frac{I_{\mathrm{E}}}{\tan (\beta}\right)
$$

where $A_{1}=\pi \operatorname{cotan}^{2}(\beta)$ is an indenter-dependent constant $\left(A_{1}=24.5\right.$ for a Berkovich tip). The term in the bracket represents the ratio between the measured contact pressure and the purely elastic limit. For a spherical indenter, the face inclination angle varies with contact depth as $\tan (\beta) \approx a / R(120)$, where $a \approx \sqrt{P /\left(H_{\mathrm{I}}\right)}$ is the contact radius, so that

$$
h_{\mathrm{r}} \approx \frac{P}{4 \pi R H_{\mathrm{I}}}\left(1-2 I_{\mathrm{E}} \sqrt{R \frac{H_{\mathrm{I}}}{P}}\right)
$$

The second term reflects the fact that 'yielding' in blunt contacts will only occur at some finite load, $P_{\mathrm{Y}}>$ $4 H_{\mathrm{I}}\left(I_{\mathrm{E}}\right)^{2} R^{2}$, which is of identical form as the prediction derived by Rhee et al. (121), but with a somewhat larger constant ( 4 compared to 0.85 , obtained by experimental calibration).

Unsurprisingly, a large work of fracture reduces the size of ensuing cracks, independent of whether the contacts are sharp or blunt. In addition, cracks are controlled by $E_{\mathrm{I}}$ in blunt contacts, and $H_{\mathrm{I}}$ in sharp contacts. Notably, the resistance to quasi-plastic deformation is not generally controlled by $H_{\mathrm{I}}$, but by the elasticity in$\operatorname{dex}, I_{\mathrm{E}}$. Assuming that wear is proportional to the size of the damage zone, these simple guidelines can be used to rank biological materials by their resistance to mechanical wear (see table 1 ).

The competition between quasi-plasticity and brittle fracture

While the previous arguments provide simple guidelines for ranking materials according to their ability to minimise the size of the damage zone(s) resulting from indentation, they do not address the question which of the damage modes is dominating, or indeed more likely to occur in the first place. In blunt contacts, materials can crack before they yield - a simple predictive index can be found by comparing the load required to initiate brittle fracture, $P_{\mathrm{C}}$, with the load required to cause quasi-plastic deformation, $P_{\mathrm{Y}}(121)$ :

$$
\frac{P_{\mathrm{Y}}}{P_{\mathrm{C}}}=A_{2} \frac{H_{\mathrm{I}}}{G_{\mathrm{c}}}\left(\frac{I_{\mathrm{E}}}{\left(1-v^{2}\right)}\right)^{2} R
$$

where $A_{2} \approx 10^{-4}$ is a dimensionless constant obtained by experimental calibration (note that Tabor's law has been used in the derivation of eq. 7, see 121). If $P_{\mathrm{Y}} / P_{\mathrm{C}}>1$, brittle fracture will dominate, while quasi-plasticity will be the dominant damage mode if $P_{\mathrm{Y}} / P_{\mathrm{C}}<1$ (121). Equation 7 also includes the radius of the indenter, $R$, illustrating that quasi-plasticity, a volume effect, and brittle fracture, a surface effect, are linked by a characteristic length scale. This length scale, and therefore the propensity of a material to crack, is set by the 'brittleness parameter', $\left(H_{\mathrm{I}} / G_{\mathrm{c}}\right) I_{\mathrm{E}}^{2} /\left(1-v^{2}\right)^{2}(121)$; large values indicate that small (but blunt) particles will likely induce a crack, whereas small values imply that the dominating damage mode will be quasi-plastic. The brittleness parameter is plotted against the load ratio for a number of biological and engineering materials in figure 4 , assuming an arbitrary particle radius of $1 \mathrm{~mm}$, and smearing the term containing Poisson's ratio into the insecurity associated with the experimental constant $A_{2}$. Even for such relatively large particles, biological materials are almost exclusively in the quasi-plastic regime, indicating that the ratio between indentation hardness and modulus is the parameters governing wear resistance.

If the wear-inducing body is sharp, yield occurs practically instantaneously, due to the divergent contact stresses. The competition between the two damage modes can then be assessed by comparing the width of the residual impression induced by quasi-plasticity, $a_{\mathrm{r}}$ (see inset in figure $4 \mathrm{~b}$ ): 

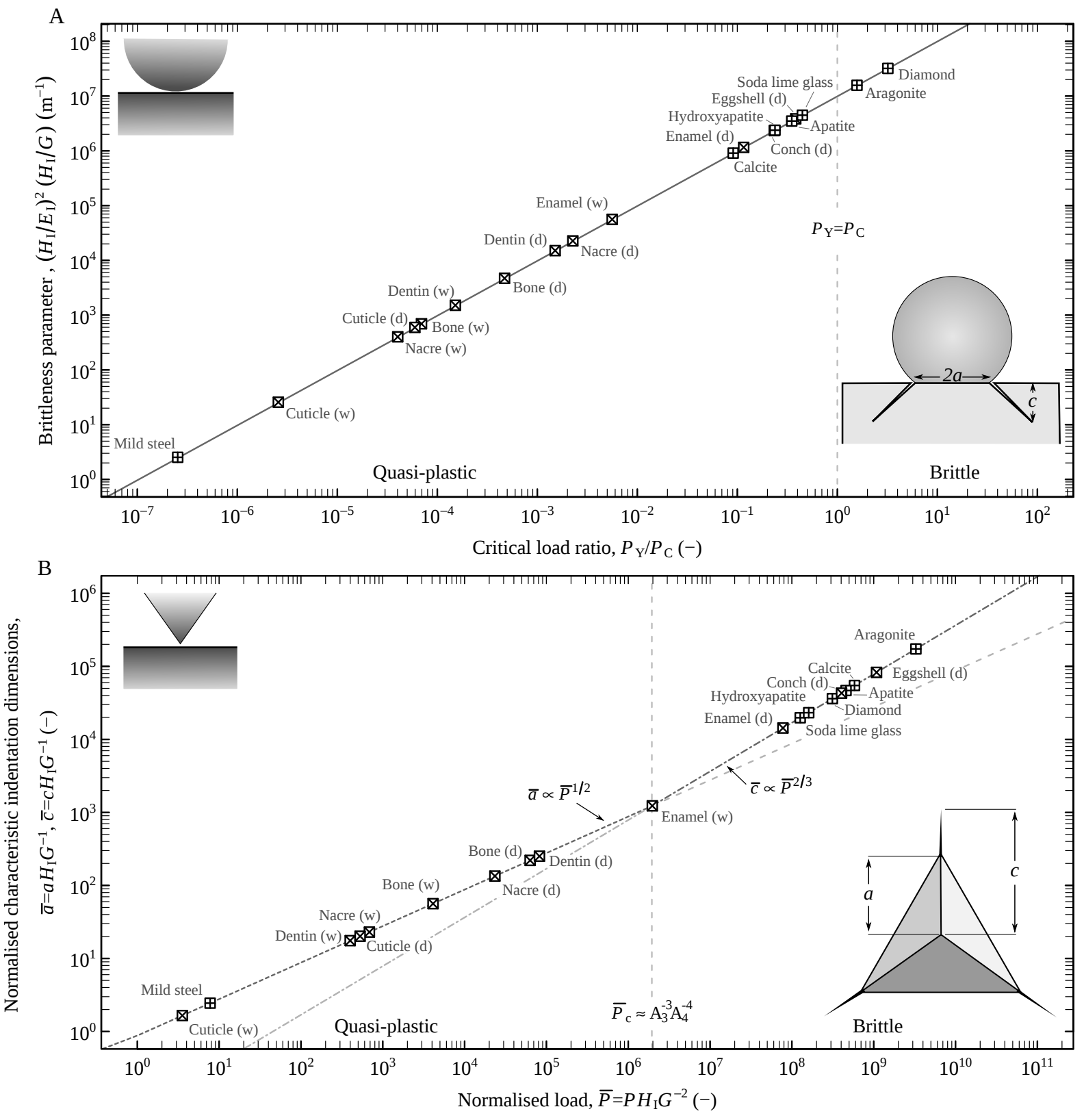

Figure 4: (A) Blunt contacts can cause damage via brittle fracture or quasi-plastic deformation. The dominating damage mode is set by a 'brittleness parameter', and the radius of curvature of the indenting body (here set to an arbitrary value of $1 \mathrm{~mm}$ ). If the ratio between the load required to initiate quasi-plastic deformation and the load to induce a crack, $P_{\mathrm{Y}} / P_{\mathrm{C}}$, is larger than one, brittle fracture will dominate, and vice versa. For $R<4 \mathrm{~mm}$, all biological materials included in this data set would be in the quasi-plastic regime. (B) If the indenter is sharp, yield is imminent. Cracks will only exceed the width of the residual impression resulting from quasi-plastic deformation once a critical load is exceeded (the normalised indentation dimensions shown here have been calculated using an arbitrary value of $P=1 \mathrm{~N}$, and $A_{3}^{3} A_{4}^{4} \approx 5.15 \cdot 10^{-7}$ for a Berkovich indenter). For $P<5 \mathrm{mN}$, none of the biological materials included in this data set would crack. Increasing or decreasing the radius of the indenting particle (for (A)) or the indentation force (for (B)) will shift the materials to the right or left, respectively. The letters in brackets indicate if measurements were performed in hydrated $(w)$ or dehydrated $(d)$ conditions. Both plots illustrate the enourmous effect of both the composite design and hydration on biological materials (compare the data for pure aragonite to nacre, hydroxyapatite with dentin and enamel, and apatite with bone); both increase the resistance to fracture by orders of magnitude. The only exception appears to be chicken eggshell. Hydrated materials are less likely to crack, because of their increased toughness, and decreased indentation hardness and modulus. Data are from (21, 122, 123, own data) (biological materials), (121) (mild steel, soda lime glass, and diamond), (62, 124) (aragonite), (125) (apatite, calcite) and $(126,127)$ (hydroxyapatite). 


$$
a_{\mathrm{r}}=\sqrt{\frac{P}{A_{3} H_{\mathrm{I}}}}
$$

with the length of the crack introduced by brittle fracture, $c$, given by eq. $4 \mathrm{~b}$ (including another geometrical constant, $A_{4}$, in the nominator). Equating eqs. 8 and $4 \mathrm{~b}$ yields an approximate prediction for the load at which $c=a_{\mathrm{r}}$, or, in other words, the load required to initiate a crack (see inset in figure 4 and 19, 128):

$$
P_{\mathrm{C}} \approx \frac{1}{A_{3}^{3} A_{4}^{4}} \frac{G_{\mathrm{c}}^{2}}{H_{\mathrm{I}}}
$$

where $A_{3}$ and $A_{4}$ are constants relating to the indenter geometry. Equations $4 \mathrm{~b}, 8$ and 9 can be used to generate a universal plot of the normalised damage lengths against the normalised indentation load, which is shown in figure 4B for an arbitrary load of $1 \mathrm{~N}$, and a Berkovich indenter, for which $A_{3}^{3} A_{4}^{4} \approx 5.15 \cdot 10^{-7}$ (for details on the normalisation, see refs. 19, 128).

While the available comparative data shown in figure 4 are limited, two conclusions emerge. First, quasiplasticity is highly competitive in biological materials (see also ref. 21, for a similar argument): Cracks would be avoided altogether if $P<2 \mathrm{mN}$ (sharp contacts), or $R<3 \mathrm{~mm}$ (blunt contacts). In contrast, shifting all investigated biological materials into the brittle fracture regime would require $P>0.6 \mathrm{MN}$ (sharp contacts), or $R>400 \mathrm{~m}$ (blunt contacts). As a consequence, even relatively large wear particles will polish rather than grind biological materials. Second, the competitiveness of quasi-plasticity appears to be largely based on a composite design and on hydration (cf. hydrated and dehydrated nacre to pure aragonite, dentin and enamel to pure hydroxyapatite, and bone to pure apatite in figure 4). If these design features play any role in damage control, it is to avoid cracking, suggesting that quasiplastic deformation may be less deleterious, or easier to control. The only exception to this rule appears to be chicken eggshell, which has a brittleness comparable to its main constituent calcite (we note that there has been some controversy about the toughness of eggshell, and other authors have reported higher values 123).

If the suggested dominance of quasi-plastic deformation is to reflect adaptation, the selective pressures that would favour it compared to brittle fracture need to be identified. A first insight can be gained from Griffith's criterion, which relates the material's strength, $\sigma$, to a characteristic flaw size, $c_{\mathrm{f}}$ :

$$
\sigma \propto \sqrt{\frac{E G_{\mathrm{c}}}{c_{\mathrm{f}}}}
$$

For sharp particles and loads smaller than $P_{\mathrm{C}}$, the relevant flaw size is $a_{\mathrm{r}} \propto P^{1 / 2}$ (see eq. 8). For loads larger than $P_{\mathrm{C}}$, however, the relevant flaw size is $c \propto P^{2 / 3}$ (see eq. $4 \mathrm{~b}$ ), so that the degradation in strength due to flaws grows at a faster rate once brittle fracture becomes the dominating fracture mode $P_{\mathrm{C}}(129)$.

\section{The elasticity index as a measure of yield strength}

One of the most well-known results of Tabor's seminal work on the hardness of metals is that indentation hardness may be used as an index for yield strength, $\sigma_{\mathrm{Y}}$, because the ratio between the two is approximately constant, $H_{\mathrm{I}} / \sigma_{\mathrm{Y}} \approx 3$. Although used frequently, it remains unclear if this approximations is also valid for biological materials.

Tabor's law can be rationalised via slip-line theory for ideally rigid-perfectly-plastic materials. However, Tabor's law overestimates the constraint factor, $\Upsilon=$ $H_{\mathrm{I}} / \sigma_{\mathrm{Y}}$ for materials that show considerable amounts of elastic deformation. Such plastic ideally-elastic solids can be analysed with expanding cavity models, which liken indentation to the expansion of a void driven by internal pressure. Yu and Blanchard (130) have proposed an expanding cavity model for elastic perfectlyplastic solids, based on the simplifying assumption that the material underneath the indenter will deform elastically until a critical pressure is reached, from where on the contact pressure is given by slip-line theory. In this model, the constraint factor $\Upsilon=H_{\mathrm{I}} / \sigma_{\mathrm{Y}}$ can be written as a function of the elasticity index, and the indenter geometry:

$$
\Upsilon=\frac{2 A_{1}}{\tan (\beta)} I_{\mathrm{E}} \frac{1}{\operatorname{atanh}\left[2 / \tan (\beta) I_{\mathrm{E}}\right]}
$$

where $A_{1}$ is a constant depending on the indenter geometry and the yield criterion (for a Berkovich tip and the von Mises yield criterion, $A_{1} \approx 2.75$. See 130 ). For $I_{\mathrm{E}}=0.05$ and a Berkovich indenter, $\Upsilon=2.67$, in reasonable agreement with Tabor's relation.

The value of these predictions is limited by the lack of experimental data to put them to a test. Trim et al. (53) reported an elasticity index of $I_{\mathrm{E}} \approx 0.055$ for the dehydrated horn of bighorn sheep (Ovis canadensis), so that $\Upsilon \approx 2.66$. The resulting prediction of $\sigma_{\mathrm{Y}} \approx$ $72 \mathrm{MPa}$ is in reasonable agreement with the average yield strength measured in compression $\left(\sigma_{\mathrm{Y}} \approx 65 \mathrm{MPa}\right.$, 
see ref. 53). The allegedly 'strongest natural material', the teeth of limpets, have a yield strength of approximately $2.25 \mathrm{GPa}$ (estimated from figure 5 in 131). Using $E=120 \mathrm{GPa}$ (131), $v=0.22$ (132), and eq. 11 yields $H_{\mathrm{I}} \approx 6 \mathrm{GPa}$, which is in reasonable agreement with the available data for pure goethitie, but considerably larger than for complex goethitie $(6.7 \mathrm{GPa}$ and $1.1 \mathrm{GPa}$, respectively, see 132). Both examples suggest that the above simple model may be an acceptable approximation in some cases, and exploring this avenue further may be a valuable effort.

\section{Conclusions and outlook}

Instrumented indentation has become the dominant tool for material characterisation on small scales. In biological materials, the primary use of indentation is to relate the measured properties to ultrastructure and function, which requires a detailed understanding of their mechanical significance. Indentation hardness is a hybrid property quantifying the resistance to both reversible and irreversible deformation, and is hence inherently linked to the elastic modulus. This link has been explored with a simple series elastic-plastic deformation model, which provided an expression for the 'true' hardness, a property independent of the modulus, facilitating a quantitative comparison of the resistance to irreversible deformation across and within structural biological materials. Indentation hardness and modulus appear to be linearly related in biological materials, and their ratio is an index for (i) the amount of relative irreversible deformation in the contact zone, (ii) the yield strength of the material, and (iii) specific types of mechanical damage. As quasi-plasticity is highly competitive with brittle fracture in biological materials, the ratio between indentation hardness and modulus can be used to rank materials by their damage resistance.

Two elephants in the room have thus far been largely ignored. First, we have repeatedly referred to 'plasticity' and 'yield', without providing any detail on what these phenomena actually involve. Both concepts are well understood in 'classic' engineering materials, but remain severely understudied in most biological materials (but see 133). Does the onset of yield involve dislocation motions and twinning along well-defined crystallographic planes, densification by compaction, phase transformations, micro-cracking, all of these or something completely different? Yield processes are unlikely to be material-invariant, so that the applicability of the previous arguments must be assessed from case to case. If yield induces microcracks, these can coalesce, in which case quasi-plasticity can be as deleterious for strength degradation, fatigue and wear resistance as brittle fracture (121), rendering it a particular problem for most biological materials. Second, most if not all biological materials are viscoelastic, so that the assumption of ideal elastic-plastic behaviour implicit in the previous analysis is unrealistic. However, comparative data on the viscoelastic properties of biological materials is almost completely absent. The data used in this study were dominantly collected with a trapezoidal load protocol, so that the measured modulus should be interpreted as a infinite-time indentation modulus (provided that the hold-period allowed sufficient time for relaxation or creep to converge). As a consequence, the estimated elasticity indices represent an upper bound. Viscoelasticity may be particularly important in damage control - as the residual stress field scales with $I_{\mathrm{E}}^{-1}$, a time-dependent modulus can relieve some of these stresses into creep or relaxation, instead of feeding them into the extension or initiation of a crack. The immediate implication of this simple argument is that wear processes in biological materials must be rate-dependent in a complex fashion, but little research has addressed this phenomenon in detail.

Another hallmark of biological materials is that their mechanical properties are hydration-dependent. A meta-analysis of the available data underlined that hydration is particularly important in soft materials, and generally strongly reduces the propensity of materials to fracture, at the cost of making them more vulnerable to quasi-plastic deformation. The mechanistic basis for the influence of hydration on toughness, modulus, and hardness remains unclear, highlighting another important area of future research.

\section{Materials \& Methods}

Indentation modulus, hardness and fracture toughness of biological materials were collated from the literature. Relevant papers were identified with google scholar, using the search terms 'biology+indentation', 'biology+hardness', and 'biological materials'. Data were either taken directly from the text or tables, or extracted from figures using the free tool WebPlotDigitizer, developed and maintained by Ankit Rohatgi (http://arohatgi.info/WebPlotDigitizer). All data can be found in the supplementary material.

\section{Acknowledgements}

The authors would like to thank the Oyen-Lab and Jan-Henning 
Dirks for fruitful discussions and helpful comments on early versions of this manuscript. This study was supported by a Senior Research Fellowship from Clare College, Cambridge (to DL).

\section{Appendix}

\section{Derivations}

We make the simplifying assumption that any deformation during indentation is either irreversible on the time scale of the experiment ('plastic') or reversible ('elastic'). The irreversible deformation is represented by a plastic component characterised by a 'true' hardness $H$, while the elastic deformation is represented by an elastic component characterised by a plane strain modulus $E^{\prime}=1 /\left(1-v^{2}\right)$. The respective constitutive relationships between force and displacement are (14)

$$
P=E^{\prime} \pi \operatorname{cotan}^{2}(\beta) \frac{\tan (\beta)}{2 \gamma_{\mathrm{e}}^{2}} h^{2}
$$

for the elastic component, and

$$
P=\frac{1}{\gamma_{\mathrm{p}}^{2}} \pi \operatorname{cotan}^{2}(\beta) H h^{2}
$$

for the plastic component $\left(\gamma_{\mathrm{e}}\right.$ and $\gamma_{\mathrm{p}}$ are constants relating to the depression or elevation of the contact perimeter. For elastic contacts, $\gamma_{\mathrm{e}}=\pi / 2$. See 14). These two components superimpose to determine the relationship between load and displacement during loading, which is of the form

$$
P=k_{1} h^{2}
$$

The load on two elements connected in series is identical to the total applied load, while the displacement is additive, so that from eqs. A1-A3 we find

$$
k_{1}=\frac{\pi \operatorname{cotan}^{2}(\beta) H}{\left(1+\sqrt{2 / \tan (\beta)} \sqrt{H / E^{\prime}}\right)^{2}}
$$

where we assumed $\gamma_{\mathrm{e}}=\gamma_{\mathrm{p}}$ to ensure compatibility at maximum load. Using $H_{\mathrm{I}}=P_{\max } /\left(\pi \operatorname{cotan}^{2}(\beta) h_{\max }^{2}\right)$ and eq. A3 yields eq. 1 in the main manuscript.

\section{Additional statistical analyses}

\section{The influence of indenter geometry on the relationship between indenation hardness and modulus}

In order to remove the variation introduced by the different indenter geometries, eq. 2 was used to calculate the 'true' hardness, $H$ for all materials, which was then rescaled into a Berkovich indentation hardness with eq. 1 . A reduced major axis regression on $\log$-transformed values yielded $H_{\mathrm{I}}=0.043 E_{\mathrm{I}}^{1.04}$ (95\% confidence intervals $(0.040 ; 0.047)$ and $\left.(1.02 ; 1.06), \mathrm{R}^{2}=0.96\right)$, almost identical to the result obtained from the original data.

\section{The sensitivity to hydration}

The sensitivity to hydration decreases with hydrated indentation modulus as $S_{\mathrm{H}}=4.40 E_{\mathrm{I}, \mathrm{w}}^{-0.84}\left(\mathrm{R}^{2}=64 \%, 95 \% \mathrm{CI}(3.26 ; 5.92)\right.$ and (-0.96; - 0.74), respectively). A number of other models are summarised in table A1. Dehydration appears to have a stronger effect on indentation modulus compared to hardness for materials with small values of $H_{\mathrm{I}, \mathrm{w}}$ and $E_{\mathrm{I}, \mathrm{w}}$, while indentation hardness is more strongly affected in the limit of large $H_{\mathrm{I}, \mathrm{w}}$ and $E_{\mathrm{I}, \mathrm{w}}$ (based on the fitted parameters of a reduced major axis linear regression on log-transformed data, see table A11). However, this statistical effect may be an artefact, first, because 'wet' contacts are likely more viscoelastic, impacting both indentation hardness and stiffness, but not necessarily in equal measures, second, because the conditions of the hydrated measurements differed between studies (some experiments were conducted in submersion, while others were conducted with 'fresh' specimen), and third, because re-hydration of previously dehydrated materials may not fully restore the initial material properties (60).

Table A1: Results of reduced major axis regressions on logtransformed data, with wet indenation hardness and modulus in GPa.

\begin{tabular}{llll}
\multicolumn{4}{l}{ The values in brackets indicate 95\% confidence intervalls. } \\
\hline Regression & Slope & Intercept & $\mathrm{R}^{2}$ \\
\hline$S_{\mathrm{H}, H_{\mathrm{I}}}$ vs. $H_{\mathrm{I}, \mathrm{w}}$ & $-0.67(-0.82 ;-0.56)$ & $-0.30(-0.43 ;-0.17)$ & 0.64 \\
$S_{\mathrm{H}, E_{\mathrm{I}}}$ vs. $H_{\mathrm{I}, \mathrm{w}}$ & $-0.90(-1.04 ;-0.78)$ & $-0.61(-0.73 ;-0.49)$ & 0.81 \\
$S_{\mathrm{H}, H_{\mathrm{I}}}$ vs. $E_{\mathrm{I}, \mathrm{w}}$ & $-0.71(-0.89 ;-0.56)$ & $0.63(0.44 ; 0.82)$ & 0.49 \\
$S_{\mathrm{H}, E_{\mathrm{I}}}$ vs. $E_{\mathrm{I}, \mathrm{w}}$ & $-0.94(-1.08 ;-0.82)$ & $0.63(0.48 ; 0.77)$ & 0.83 \\
\hline
\end{tabular}

\section{References}

[1] P. Fratzl, Biomimetic materials research: what can we really learn from nature's structural materials?, Journal of the Royal Society Interface 4 (15) (2007) 637-642.

[2] J. Aizenberg, P. Fratzl, Biological and biomimetic materials, Advanced Materials 21 (4) (2009) 387-388.

[3] P.-Y. Chen, J. McKittrick, M. A. Meyers, Biological materials: functional adaptations and bioinspired designs, Progress in Materials Science 57 (8) (2012) 1492-1704.

[4] M. A. Meyers, J. McKittrick, P.-Y. Chen, Structural biological materials: critical mechanics-materials connections, science 339 (6121) (2013) 773-779.

[5] U. G. Wegst, H. Bai, E. Saiz, A. P. Tomsia, R. O. Ritchie, Bioinspired structural materials, Nature materials 14 (2014) 23-26.

[6] A. Gouldstone, N. Chollacoop, M. Dao, J. Li, A. M. Minor, Y.L. Shen, Indentation across size scales and disciplines: Recent developments in experimentation and modeling, Acta Materialia 55 (12) (2007) 4015-4039.

[7] M. L. Oyen, R. F. Cook, A practical guide for analysis of nanoindentation data, Journal of the mechanical behavior of biomedical materials 2 (4) (2009) 396-407. 
[8] D. B. Marshall, R. F. Cook, N. P. Padture, M. L. Oyen, A. Pajares, J. E. Bradby, I. E. Reimanis, R. Tandon, T. F. Page, G. M. Pharr, B. Lawn, The compelling case for indentation as a functional exploratory and characterization tool, J Am Ceram Soc 98 (9) (2015) 2671-2680.

[9] M. Launey, R. Ritchie, On the fracture toughness of advanced materials, Advanced Materials 21 (20) (2009) 2103-2110.

[10] R. O. Ritchie, The conflicts between strength and toughness, Nature materials 10 (11) (2011) 817-822.

[11] J. J. Kruzic, D. K. Kim, K. J. Koester, R. O. Ritchie, Indentation techniques for evaluating the fracture toughness of biomaterials and hard tissues, Journal of the Mechanical Behavior of Biomedical Materials 2 (4) (2009) 384-395.

[12] D. M. Marsh, Plastic flow and fracture of glass, Proceedings of the Royal Society of London. Series A, Mathematical and Physical Sciences 282 (1388) (1964) 33-43.

[13] Y.-T. Cheng, C.-M. Cheng, Relationships between hardness, elastic modulus, and the work of indentation, Applied physics letters 73 (5) (1998) 614-616.

[14] M. Sakai, The meyer hardness: A measure for plasticity?, J Mater Res 14 (09) (1999) 3630-3639.

[15] Y.-T. Cheng, C.-M. Cheng, What is indentation hardness?, Surface and Coatings Technology 133 (2000) 417-424.

[16] M. Oyen, Analytical techniques for indentation of viscoelastic materials, Philosophical Magazine 86 (33-35) (2006) 56255641 .

[17] M. Sakai, Elastoplastic indentation contact mechanics of homogeneous materials and coating-substrate systems, in: O. Tabata, T. Tsuchiya (Eds.), Reliability of MEMS: Testing of Materials and Devices, Wiley-VCH Verlag GmbH \& Co. KGaA, 2008, pp. 27-65.

[18] D. Tabor, The hardness of metals, Oxford university press, 2000.

[19] B. Lawn, D. Marshall, Hardness, toughness, and brittlenessan indentation analysis, J Am Ceram Soc 62 (7) (1979) 347350 .

[20] J. J. Gilman, Chemistry and physics of mechanical hardness, Vol. 5, John Wiley \& Sons, 2009.

[21] S. Amini, A. Miserez, Wear and abrasion resistance selection maps of biological materials, Acta biomaterialia 9 (8) (2013) 7895-7907.

[22] S. Enders, N. Barbakadze, S. Gorb, E. Arzt, Exploring biological surfaces by nanoindentation, J Mater Res 19 (3) (2004) 880-887. doi:10.1016/S1748-0132(06)70077-9.

[23] N. Barbakadze, S. Enders, S. Gorb, E. Arzt, Local mechanical properties of the head articulation cuticle in the beetle Pachnoda marginata (Coleoptera, Scarabaeidae), J Exp Biol 209 (2006) 722-730. doi:10.1242/jeb.02065.
[24] J.-y. Sun, J. Tong, Fracture toughness properties of three different biomaterials measured by nanoindentation, Journal of Bionic Engineering 4 (1) (2007) 11-17.

[25] Y. Politi, M. Priewasser, E. Pippel, P. Zaslansky, J. Hartmann, S. Siegel, C. Li, F. G. Barth, P. Fratzl, A spider's fang: How to design an injection needle using chitin-based composite material, Advanced Functional Materials 22 (12) (2012) 25192528.

[26] A. Miserez, Y. Li, J. H. Waite, F. Zok, Jumbo squid beaks: Inspiration for design of robust organic composites, Acta Biomaterialia 3 (1) (2007) 139-149.

[27] S. Bentov, P. Zaslansky, A. Al-Sawalmih, A. Masic, P. Fratzl, A. Sagi, A. Berman, B. Aichmayer, Enamel-like apatite crown covering amorphous mineral in a crayfish mandible, Nature communications 3 (2012) 839-.

[28] L. B. Whitenack, D. C. Simkins, P. J. Motta, M. Hirai, A. Kumar, Young's modulus and hardness of shark tooth biomaterials, archives of oral biology 55 (3) (2010) 203-209.

[29] H. Rhee, M. Horstemeyer, Y. Hwang, H. Lim, H. El Kadiri, W. Trim, A study on the structure and mechanical behavior of the terrapene carolina carapace: A pathway to design bioinspired synthetic composites, Materials Science and Engineering: C 29 (8) (2009) 2333-2339.

[30] A. J. Goetz, E. Griesshaber, R. Abel, T. Fehr, B. Ruthensteiner, W. Schmahl, Tailored order: The mesocrystalline nature of sea urchin teeth, Acta biomaterialia 10 (9) (2014) 3885-3898.

[31] J. Lv, Y. Jiang, D. Zhang, Structural and mechanical characterization of atrina pectinata and freshwater mussel shells, Journal of Bionic Engineering 12 (2) (2015) 276-284.

[32] M. Müller, M. Olek, M. Giersig, H. Schmitz, Micromechanical properties of consecutive layers in specialized insect cuticle: the gula of Pachnoda marginata (coleoptera, scarabaeidae) and the infrared sensilla of Melanophila acuminata (coleoptera, buprestidae), Journal of Experimental Biology 211 (16) (2008) 2576-2583.

[33] B. Cribb, C.-L. Lin, L. Rintoul, R. Rasch, J. Hasenpusch, H. Huang, Hardness in arthropod exoskeletons in the absence of transition metals, Acta Biomater 6 (8) (2010) 3152-3156.

[34] B. W. Cribb, A. Stewart, H. Huang, R. Truss, B. Noller, R. Rasch, M. P. Zalucki, Insect mandibles-comparative mechanical properties and links with metal incorporation, Naturwissenschaften 95 (1) (2008) 17-23.

[35] T. Schoeberl, I. L. Jaeger, Wet or dry - hardness, stiffness and wear resistance of biological materials on the micron scale, Advanced Engineering Materials 8 (11) (2006) 1164-1169.

[36] H. C. Lichtenegger, T. Schöberl, M. H. Bartl, H. Waite, G. D. Stucky, High abrasion resistance with sparse mineralization: copper biomineral in worm jaws, Science 298 (5592) (2002) 389-392.

[37] D. Losic, K. Short, J. G. Mitchell, R. Lal, N. H. Voelcker, Afm nanoindentations of diatom biosilica surfaces, Langmuir 23 (9) (2007) 5014-5021. 
[38] A. Pérez-Huerta, M. Cusack, W. Zhu, J. England, J. Hughes, Material properties of brachiopod shell ultrastructure by nanoindentation, Journal of the Royal Society Interface 4 (12) (2007) 33-39.

[39] M. Dickinson, Mechanical properties of an arthropod exoskeleton, Hysitron Application Note.

[40] J. C. Weaver, Q. Wang, A. Miserez, A. Tantuccio, R. Stromberg, K. N. Bozhilov, P. Maxwell, R. Nay, S. T. Heier, E. DiMasi, et al., Analysis of an ultra hard magnetic biomineral in chiton radular teeth, Materials Today 13 (1) (2010) 4252.

[41] L. Sachs, J. Hedderich, Angewandte Statistik: Methodensammlung mit R, Springer-Verlag Berlin Heidelberg, Berlin Heidelberg New York, 2006. doi:10.1007/978-3-540-321613.

[42] J.-y. Sun, J. Tong, Y.-h. Ma, Nanomechanical behaviours of cuticle of three kinds of beetle, Journal of Bionic Engineering 5 (2008) 152-157.

[43] Z. X. Yang, Z. H. Liu, Z. D. Dai, Surface texture and mechanical behavior of claw material in beetle dorcus titanus (coleoptera: Lucanidae), Applied Mechanics and Materials 461 (2014) 305-312.

[44] C. M. Hayot, S. Enders, A. Zera, J. A. Turner, Nanoindentation to quantify the effect of insect dimorphism on the mechanical properties of insect rubberlike cuticle, Journal of Materials Research 28 (18) (2013) 2650-2659.

[45] C. S. Sample, A. K. Xu, S. M. Swartz, L. J. Gibson, Nanomechanical properties of wing membrane layers in the house cricket (acheta domesticus linnaeus), Journal of insect physiology 74 (2015) 10-15.

[46] J. Lian, J. Wang, Microstructure and mechanical anisotropy of crab cancer magister exoskeletons, Experimental Mechanics 54 (2) (2014) 229-239.

[47] Y. Seki, S. G. Bodde, M. A. Meyers, Toucan and hornbill beaks: A comparative study, Acta Biomaterialia 6 (2) (2010) 331-343.

[48] P.-Y. Chen, J. Schirer, A. Simpson, R. Nay, Y.-S. Lin, W. Yang M. I. Lopez, J. Li, E. A. Olevsky, M. A. Meyers, Predation versus protection: Fish teeth and scales evaluated by nanoindentation, Journal of Materials Research 27 (01) (2012) 100-112.

[49] M.-C. G. Klein, J. K. Deuschle, S. N. Gorb, Material properties of the skin of the kenyan sand boa gongylophis colubrinus (squamata, boidae), Journal of Comparative Physiology A 196 (9) (2010) 659-668.

[50] M.-C. G. Klein, S. N. Gorb, Epidermis architecture and material properties of the skin of four snake species, Journal of The Royal Society Interface 9 (76) (2012) 3140-3155.

[51] O. Franke, K. Durst, V. Maier, M. GÃ $\llbracket$ ken, T. Birkholz, H. Schneider, F. Hennig, K. Gelse, Mechanical properties of hyaline and repair cartilage studied by nanoindentation, Acta Biomaterialia 3 (6) (2007) 873-881.
[52] N. Holten-Andersen, G. E. Fantner, S. Hohlbauch, J. H. Waite, F. W. Zok, Protective coatings on extensible biofibres, Nature materials 6 (9) (2007) 669-672.

[53] M. W. Trim, M. Horstemeyer, H. Rhee, H. El Kadiri, L. N. Williams, J. Liao, K. B. Walters, J. McKittrick, S.-J. Park, The effects of water and microstructure on the mechanical properties of bighorn sheep (ovis canadensis) horn keratin, Acta biomaterialia 7 (3) (2011) 1228-1240.

[54] J. J. Lees, L. P. Folkow, R. L. Nudds, J. R. Codd, The effects of season and sex upon the morphology and material properties of keratin in the svalbard rock ptarmigan (lagopus muta hyperborea), Journal of thermal biology 44 (2014) 126-130.

[55] C. Merkel, J. Deuschle, E. Griesshaber, S. Enders, E. Steinhauser, R. Hochleitner, U. Brand, W. W. Schmahl, Mechanical properties of modern calcite-(mergerlia truncata) and phosphate-shelled brachiopods (discradisca stella and lingula anatina) determined by nanoindentation, Journal of structural biology 168 (3) (2009) 396-408.

[56] Y. Lin, C. Wei, E. Olevsky, M. A. Meyers, Mechanical properties and the laminate structure of arapaima gigas scales, Journal of the mechanical behavior of biomedical materials 4 (7) (2011) 1145-1156.

[57] G. Kaupp, M. R. Naimi-Jamal, Nutshells' mechanical response: from nanoindentation and structure to bionics models, Journal of Materials Chemistry 21 (23) (2011) 8389-8400.

[58] M. Erko, M. A. Hartmann, I. Zlotnikov, C. V. Serrano, P. Fratzl, Y. Politi, Structural and mechanical properties of the arthropod cuticle: comparison between the fang of the spider cupiennius salei and the carapace of american lobster homarus americanus, Journal of structural biology 183 (2) (2013) 172179.

[59] W. Huang, X. Wang, Biomimetic design of elastomer surface pattern for friction control under wet conditions, Bioinspiration \& Biomimetics 8 (4) (2013) 046001-.

[60] D. Klocke, H. Schmitz, Material properties of photomechanical infrared receptors in pyrophilous melanophila beetles and aradus bugs, Acta biomaterialia 8 (9) (2012) 3392-3399.

[61] D. Klocke, H. Schmitz, Water as a major modulator of the mechanical properties of insect cuticle, Acta Biomater 7 (7) (2011) 2935-2942.

[62] L. Romana, P. Thomas, P. Bilas, J. Mansot, M. Merrifiels, Y. Bercion, D. A. Aranda, Use of nanoindentation technique for a better understanding of the fracture toughness of strombus gigas conch shell, Materials characterization 76 (2013) 55-68.

[63] A. Miserez, J. C. Weaver, P. B. Pedersen, T. Schneeberk, R. T. Hanlon, D. Kisailus, H. Birkedal, Microstructural and biochemical characterization of the nanoporous sucker rings from Dosidicus gigas, Advanced Materials 21 (4) (2009) 401-406.

[64] B. Bruet, H. Qi, M. Boyce, R. Panas, K. Tai, L. Frick, C. Ortiz, Nanoscale morphology and indentation of individual nacre tablets from the gastropod mollusc trochus niloticus, Journal of Materials Research 20 (09) (2005) 2400-2419. 
[65] F. Barthelat, C.-M. Li, C. Comi, H. D. Espinosa, Mechanical properties of nacre constituents and their impact on mechanical performance, Journal of Materials Research 21 (08) (2006) 1977-1986.

[66] D. J. Scurr, S. J. Eichhorn, Analysis of local deformation in indented ensis siliqua mollusk shells using raman spectroscopy, Journal of materials research 21 (12) (2006) 3099-3108.

[67] S. W. Lee, G. H. Kim, C. S. Choi, Characteristic crystal orientation of folia in oyster shell, crassostrea gigas, Materials Science and Engineering: C 28 (2) (2008) 258-263.

[68] L. Farran, A. R. Ennos, S. J. Eichhorn, Microindentation and nanoindentation of human fingernails at varying relative humidity, Journal of Materials Research 24 (03) (2009) 980-984.

[69] B. Bhushan, W. Tang, S. Ge, Nanomechanical characterization of skin and skin cream, Journal of microscopy 240 (2) (2010) 135-144.

[70] B. Bhushan, W. Tang, Surface, tribological, and mechanical characterization of synthetic skins for tribological applications in cosmetic science, Journal of applied polymer science 120 (5) (2011) 2881-2890.

[71] B. Achrai, H. D. Wagner, Micro-structure and mechanical properties of the turtle carapace as a biological composite shield, Acta biomaterialia 9 (4) (2013) 5890-5902.

[72] M. Tadayon, S. Amini, A. Masic, A. Miserez, The mantis shrimp saddle: A biological spring combining stiffness and flexibility, Advanced Functional Materials 25 (41) (2015) 6437-6447.

[73] C. Moureaux, A. Pérez-Huerta, P. Compère, W. Zhu, T. Leloup, M. Cusack, P. Dubois, Structure, composition and mechanical relations to function in sea urchin spine, Journal of structural biology 170 (1) (2010) 41-49.

[74] X. Li, P. Nardi, Micro/nanomechanical characterization of a natural nanocomposite material?the shell of pectinidae, Nanotechnology 15 (1) (2004) 211.

[75] P. W. Lucas, P. J. Constantino, J. Chalk, C. Ziscovici, B. W. Wright, D. M. Fragaszy, D. A. Hill, J. J. Lee, H. Chai, B. W. Darvell, Indentation as a technique to assess the mechanical properties of fallback foods, American journal of physical anthropology 140 (4) (2009) 643-652.

[76] N. Lee, M. Horstemeyer, H. Rhee, B. Nabors, J. Liao, L. N. Williams, Hierarchical multiscale structure-property relationships of the red-bellied woodpecker (Melanerpes carolinus) beak, Journal of The Royal Society Interface 11 (96) (2014) 20140274-.

[77] K. Zhang, F. Si, H. Duan, J. Wang, Microstructures and mechanical properties of silks of silkworm and honeybee, Acta biomaterialia 6 (6) (2010) 2165-2171.

[78] V. Zheden, W. Klepal, S. N. Gorb, A. Kovalev, Mechanical properties of the cement of the stalked barnacle dosima fascicularis (cirripedia, crustacea), Interface focus 5 (1) (2015) 20140049-.
[79] C. M. Teniswood, D. Roberts, W. R. Howard, J. E. Bradby, A quantitative assessment of the mechanical strength of the polar pteropod limacina helicina antarctica shell, ICES Journal of Marine Science: Journal du Conseil (2013) fst100.

[80] M. Yu, I. Hermann, Z. Dai, N. Gitis, Mechanical and frictional properties of the elytra of five species of beetles, Journal of Bionic Engineering 10 (1) (2013) 77-83.

[81] T. Zhang, Y. Ma, K. Chen, M. Kunz, N. Tamura, M. Qiang, J. Xu, L. Qi, Structure and mechanical properties of a pteropod shell consisting of interlocked helical aragonite nanofibers, Angewandte Chemie 123 (44) (2011) 10545-10549.

[82] J. Enax, O. Prymak, D. Raabe, M. Epple, Structure, composition, and mechanical properties of shark teeth, Journal of structural biology 178 (3) (2012) 290-299.

[83] F. D. Fleischli, M. Dietiker, C. Borgia, R. Spolenak, The influence of internal length scales on mechanical properties in natural nanocomposites: a comparative study on inner layers of seashells, Acta biomaterialia 4 (6) (2008) 1694-1706.

[84] Y.-R. Jeng, C.-P. Mao, K.-T. Wu, Instrumented indentation investigation on the viscoelastic properties of porcine cartilage, Journal of Bionic Engineering 10 (4) (2013) 522-531.

[85] B. Juarez-de la Rosa, J. Munoz-Saldana, D. Torres-Torres, P.L. Ardisson, J. Alvarado-Gil, Nanoindentation characterization of the micro-lamellar arrangement of black coral skeleton, Journal of structural biology 177 (2) (2012) 349-357.

[86] N. Rodriguez-Florez, M. L. Oyen, S. J. Shefelbine, Insight into differences in nanoindentation properties of bone, Journal of the mechanical behavior of biomedical materials 18 (2013) 90-99.

[87] A. Miserez, T. Schneberk, C. Sun, F. W. Zok, J. H. Waite, The transition from stiff to compliant materials in squid beaks, Science 319 (5871) (2008) 1816-1819.

[88] P. Alam, S. Amini, M. Tadayon, A. Miserez, A. Chinsamy, Properties and architecture of the sperm whale skull amphitheatre, Zoology (2015) -.

[89] S. S. Singh, M. A. Jansen, N. M. Franz, N. Chawla, Microstructure and nanoindentation of the rostrum of curculio longinasus chittenden, 1927 (coleoptera: Curculionidae), Materials Characterization (2016) -.

[90] A. N. Gent, On the relation between indentation hardness and young's modulus, Rubber Chemistry and Technology 31 (4) (1958) 896-906.

[91] J. Gilman, Escape of dislocations from bound states by tunneling, J Appl Phys 39 (13) (1968) 6086-6090.

[92] G. Beckmann, Über den zusammenhang zwischen kompressibilität und härte von mineralen und nichtmetallischen kristallinen substanzen, Kristall und Technik 6 (1) (1971) 109117.

[93] A. Gerk, The effect of work-hardening upon the hardness of solids: minimum hardness, J Mater Sci 12 (4) (1977) 735-738. 
[94] R. J. Goble, S. D. Scott, Relationship between mineral hardness and compressibility(or bulk modulus), Canadian Mineralogist 23 (2) (1985) 273-85.

[95] W. Yang, R. G. Parr, L. Uytterhoeven, New relation between hardness and compressibility of minerals, Physics and Chemistry of Minerals 15 (2) (1987) 191-195.

[96] V. Lorenzo, J. M. Pereña, J. M. G. Fatou, Relationships between mechanical properties and microhardness of polyethylenes, Die Angewandte Makromolekulare Chemie 172 (1) (1989) 25-35.

[97] D. M. Teter, Computational alchemy: the search for new superhard materials, Mrs Bulletin 23 (01) (1998) 22-27.

[98] A. e. Flores, F. J. B. Calleja, G. E. Attenburrow, D. C. Bassett, Microhardness studies of chain-extended pe: Iii. correlation with yield stress and elastic modulus, Polymer 41 (14) (2000) 5431-5435

[99] X.-Q. Chen, H. Niu, D. Li, Y. Li, Modeling hardness of polycrystalline materials and bulk metallic glasses, Intermetallics 19 (9) (2011) 1275-1281.

[100] H. Bückle, Progress in micro-indentation hardness testing, Metallurgical Reviews 4 (1) (1959) 49-100.

[101] N. A. Stilwell, D. Tabor, Elastic recovery of conical indentations, Proceedings of the Physical Society 78 (2) (1961) 169.

[102] M. L. Oyen, Nanoindentation hardness of mineralized tissues, Journal of biomechanics 39 (14) (2006) 2699-2702.

[103] A. M. Peattie, D. Labonte, M. Sprenger, W. Federle, M. L. Oyen, Mechanical anisotropy of the adhesiveand tarsal setae from the tarantula, Grammostola rosea, In preparation.

[104] J. L. Hay, W. C. Olive, A. Bolshakov, G. M. Pharr, Using the ratio of loading slope and elastic stiffness to predict pile-up and constraint factor during indentation, in: MRS Proceedings, Vol. 522, Cambridge Univ Press, 1998, p. 101.

[105] A. Bolshakov, G. M. Pharr, Influences of pileup on the measurement of mechanical properties by load and depth sensing indentation techniques, Journal of materials research 13 (04) (1998) 1049-1058.

[106] J. F. Vincent, U. G. Wegst, Design and mechanical properties of insect cuticle, Arthropod Struct Dev 33 (2004) 187-199.

[107] S. Lee, E. E. Novitskaya, B. Reynante, J. Vasquez, R. Urbaniak, T. Takahashi, E. Woolley, L. Tombolato, P.-Y. Chen, J. McKittrick, Impact testing of structural biological materials, Materials Science and Engineering: C 31 (4) (2011) 730-739.

[108] J. Dirks, M. Li, A. Kabla, W. Federle, In vivo dynamics of the internal fibrous structure in smooth adhesive pads of insects, Acta Biomater 8 (7) (2012) 2730-2736.

[109] B. Bayerlein, L. Bertinetti, B. Bar-On, H. Blumtritt, P. Fratzl, I. Zlotnikov, Inherent role of water in damage tolerance of the prismatic mineral-organic biocomposite in the shell of pinna nobilis, Advanced Functional Materials (2016) -.
[110] J. E. Hillerton, J. F. Vincent, J., The specific location of zinc in insect mandibles, J Exp Biol 101 (1) (1982) 333-336.

[111] D. L. Quicke, P. Wyeth, P, J. D. Fawke, H. H. Basibuyuk, J. F Vincent, Manganese and zinc in the ovipositors and mandibles of hymenopterous insects, Zool J Linn Soc 124 (4) (1998) 387-396.

[112] R. M. Schofield, M. H. Nesson, K. A. Richardson, Tooth hardness increases with zinc-content in mandibles of young adult leaf-cutter ants, Naturwissenschaften 89 (12) (2002) 579-583.

[113] G. M. Erickson, B. A. Krick, M. Hamilton, G. R. Bourne, M. A. Norell, E. Lilleodden, W. G. Sawyer, Complex dental structure and wear biomechanics in hadrosaurid dinosaurs, Science 338 (6103) (2012) 98-101.

[114] J. A. Williams, Wear and wear particles - some fundamentals, Tribology International 38 (10) (2005) 863-870.

[115] F. Zok, A. Miserez, Property maps for abrasion resistance of materials, Acta materialia 55 (18) (2007) 6365-6371.

[116] B. R. Lawn, J. J.-W. Lee, H. Chai, Teeth: among nature's most durable biocomposites, Annual Review of Materials Research 40 (2010) 55-75.

[117] B. R. Lawn, E. R. Fuller, Equilibrium penny-like cracks in indentation fracture, Journal of Materials Science 10 (12) (1975) 2016-2024.

[118] G. R. Anstis, P. Chantikul, B. R. Lawn, D. B. Marshall, A critical evaluation of indentation techniques for measuring fracture toughness: I, direct crack measurements, Journal of the American Ceramic Society 64 (9) (1981) 533-538.

[119] B. R. Lawn, A. Evans, D. Marshall, Elastic/plastic indentation damage in ceramics: the median/radial crack system, Journal of the American Ceramic Society 63 (9-10) (1980) 574-581.

[120] K. L. Johnson, Contact mechanics, Cambridge university press, 1987.

[121] Y.-W. Rhee, H.-W. Kim, Y. Deng, B. R. Lawn, Brittle fracture versus quasi plasticity in ceramics: a simple predictive index, J Am Ceram Soc 84 (3) (2001) 561-565.

[122] J.-H. Dirks, D. Taylor, Fracture toughness of locust cuticle, The Journal of experimental biology 215 (9) (2012) 15021508 .

[123] D. Taylor, M. Walsh, A. Cullen, P. O'Reilly, The fracture toughness of eggshell, Acta biomaterialia 37 (2016) 21-27.

[124] L. J. Gibson, M. F. Ashby, B. A. Harley, Cellular materials in nature and medicine, Cambridge University Press, 2010.

[125] M. E. Broz, R. F. Cook, D. L. Whitney, Microhardness, toughness, and modulus of mohs scale minerals, American Mineralogist 91 (1) (2006) 135-142.

[126] M. B. Thomas, R. H. Doremus, Fracture strength of dense hydroxylapatite, AM. CERAM. SOC. BULL. Am. Ceram. Soc. Bull. 60 (2) (1981) 258. 

available under aCC-BY 4.0 International license.

[127] S. Saber-Samandari, K. A. Gross, Micromechanical properties of single crystal hydroxyapatite by nanoindentation, Acta Biomaterialia 5 (6) (2009) 2206-2212.

[128] A. Miserez, J. C. Weaver, P. J. Thurner, J. Aizenberg, Y. Dauphin, P. Fratzl, D. E. Morse, F. W. Zok, Effects of laminate architecture on fracture resistance of sponge biosilica: lessons from nature, Advanced Functional Materials 18 (8) (2008) 1241-1248.

[129] B. R. Lawn, Fracture and deformation in brittle solids: a perspective on the issue of scale, Journal of materials research 19 (01) (2004) 22-29.

[130] W. Yu, J. P. Blanchard, An elastic-plastic indentation model and its solutions, Journal of materials research 11 (09) (1996) 2358-2367.

[131] A. H. Barber, D. Lu, N. M. Pugno, Extreme strength observed in limpet teeth, Journal of The Royal Society Interface 12 (105) (2015) -

[132] D. Chicot, J. Mendoza, A. Zaoui, G. Louis, V. Lepingle, F. Roudet, J. Lesage, Mechanical properties of magnetite (fe 3 o 4 ), hematite ( $\alpha$-fe 2 o 3 ) and goethite ( $\alpha$-feo-oh) by instrumented indentation and molecular dynamics analysis, Materials Chemistry and Physics 129 (3) (2011) 862-870.

[133] S. Amini, M. Tadayon, S. Idapalapati, A. Miserez, The role of quasi-plasticity in the extreme contact damage tolerance of the stomatopod dactyl club, Nature materials (14) (2015) 943950 . 